Pathophysiology of Haemostasis and Thrombosis
Pathophysiol Haemost Thromb 2003;33:64-67

DOI: $10.1159 / 000073848$
Received: September 17, 2002

Accepted after revision: April 7, 2003

\title{
Changes in Bone Density during Long-Term Administration of Low-Molecular-Weight Heparins or Acenocoumarol for Secondary Prophylaxis of Venous Thromboembolism
}

\author{
L. Wawrzyńska ${ }^{a} \quad$ W.Z. Tomkowski ${ }^{a} \quad$ J.Przedlacki $^{b} \quad$ B. Hajduk ${ }^{\text {a }} \quad$ A. Torbicki ${ }^{a}$ \\ a Department of Internal Chest Medicine, Institute of Tuberculosis and Lung Diseases, and \\ bDepartment of Internal Medicine and Nephrology, Medical University, Warsaw, Poland
}

\section{Key Words}

LMWH · Acenocoumarol · Bone mineral density ·

Osteoporosis

\begin{abstract}
Background: Indications for long-term anticoagulation are expanding. Osteoporosis is a complication which can develop after prolonged treatment with unfractionated heparin and is probably multifactorial. Data on osteoporosis associated with low-molecular-weight heparins (LMWH) are contradictory. Vitamin K participates in bone metabolism and since oral anticoagulants antagonize vitamin K, their use may also increase the risk of osteoporosis. Aim: To assess and compare the effects of longterm secondary venous thromboembolic prophylaxis with LMWH or acenocoumarol on bone structure. Methods: We assessed bone mineral density (BMD) by densitometry in 86 patients receiving LMWH or acenocoumarol for 3-24 months. The initial BMD was compared to the final result expressed as the percentage difference. The Z-score was also assessed and defined for individual patients as the number of standard deviations of BMD from its ideal value calculated for age and sex groups.
\end{abstract} Results: Excessive decrease in BMD was evidenced, which seemed to relate to the duration as well as type of treatment. At 1 and 2 years of follow-up, the mean decrease in BMD of the femur was $1.8 \%$ and $2.6 \%$ in patients on acenocoumarol and 3.1 and $4.8 \%$ in patients on enoxaparin, respectively. Conclusions: Long-term exposure to treatment and prophylaxis of venous thromboembolism cause a modest but progressive decrease in BMD, more evident in patients on LMWH than on acenocoumarol. It might be advisable to perform densitometry before starting long-term anticoagulation and to repeat it every 12 months, especially in patients with concomitant risk factors for osteoporosis in order to identify patients in need of its prophylaxis.

Copyright $@ 2003$ S. Karger AG, Basel

\section{Introduction}

The increasing spectrum of indications for low-molecular-weight heparin (LMWH) and vitamin K antagonists requires consideration of potential side effects, especially during prolonged administration.

Osteopenia and osteoporosis are rare complications, which can develop after prolonged anticoagulation. Reports in the mid-sixties of patients with spontaneous frac-

\begin{tabular}{ll}
\hline KARGER & ( ) 2003 S. Karger AG, Basel \\
Fax + 4161306 12 34-8832/03/0332-0064\$19.50/0 \\
$\begin{array}{l}\text { E-Mail karger@karger.ch } \\
\text { www.karger.com }\end{array}$ & $\begin{array}{l}\text { Accessible online at: } \\
\text { www.karger.com/pht }\end{array}$
\end{tabular}

Liliana Wawrzyńska, MD, PhD

Department of Chest Medicine, Institute of Tuberculosis and Lung Disease

Plocka 26 street

PL-01-138 Warsaw (Poland)

Tel. +48 22431 2154, Fax +48 22431 2414, E-Mail l.wawrzynska@igichp.edu.pl 
tures during long-term treatment with heparin first drew attention to a possible relationship between heparin treatment and osteoporosis [1]. Heparin-associated osteoporosis is a rare but potentially serious complication of unfractionated heparin (UFH) and LMWH therapy. Most of the reported cases of symptomatic osteoporosis with spontaneous fractures occurred in pregnant women treated with UFH for recurrent thromboembolism [2, 3].

A practical way to evaluate the relationship between heparins and osteoporosis is to use bone density measurements by dual X-ray absorptiometry (DEXA) of the lumbar spine. Barbour et al. [4] in 1994, showed that heparin adversely affected bone density in about one third of exposed pregnant women. These results confirmed those obtained by Ginsberg et al. [5] in 1990. Studies addressing the mechanism of heparin-associated osteoporosis have been performed in both animals and humans; although meaningful data have been forthcoming, some remain conflicting. [6-8].

Heparin-induced osteoporosis may be caused by one or more of the following factors: overactivation of osteoclasts by parathyroid hormone, decreased activity of osteoblasts, increased bone resorption as a result of collagen activation and disturbances in the metabolism of vita$\min \mathrm{D}$.

The first two mechanisms are expected to result from the affinity of heparin for $\mathrm{Ca}^{2+}$. This leads to calcium decrease in blood and hence to stimulation of parathyroid glands that produce PTH which, in turn, stimulates osteoclasts that damage the bone. The side effect of this process is supposed to enhance the activity of osteoblasts necessary for bone reconstruction [9].

Histomorphometric analysis showed both a time- and dose-dependent decrease in trabecular bone volume after UFH treatment. Heparin-treated rats also showed a decrease in serum alkaline phosphatase and an increase in urinary pyridinoline. Both UFH and LMWH decreased osteoblast and osteoid surface to a similar extent, but only UFH increased osteoclast surface [10, 11]. LMWH causes less calcium loss than UFH.

Calcium release was increased in a dose-dependent manner by the addition of either UFH or LMWH, but more than 50-fold higher LMWH concentrations were needed to obtain an effect equivalent to UFH [12].

Vitamin $\mathrm{K}$ is an essential factor for the synthesis of plasma-clotting proteins and site-specific carboxylation of bone $\gamma$-carboxyglutamate (GLA) protein and other bone matrix proteins. A low vitamin $\mathrm{K}$ concentration has been associated with reduced bone mineral density (BMD) [13]. One of the first studies which might indirectly refer to inhibition of bone matrix proteins indicated that vitamin $\mathrm{K}$ antagonists inhibit enzymatic outer ring monodeiodination of $\mathrm{T}_{4}$ to $\mathrm{T}_{3}$ [14]. This inhibition of conversion of $T_{4}$ to $T_{3}$ may explain other adverse effects of this drug. The same applies for bones.

Vitamin K antagonists are widely used in patients with atrial fibrillation, venous thromboembolic disease, ischemic heart disease, and in patients with mechanical heart valves. Divergent results have been obtained in studies of BMD in these patients.

The aim of this nonrandomized, open-label, prospective study was to estimate the influence of anticoagulant treatment for venous thromboembolism (VTE) on bone density when using LMWH or acenocoumarol.

\section{Methods}

The study group consisted of 86 patients ( 45 females, 45 males; mean age 48.1 years, range 22-74 years) assigned to secondary prophylaxis after episodes of VTE.

The spectrum of patients admitted to our hospital includes people living in rural areas or small communities where appropriate INR monitoring was more difficult than self-injection of LMWH. Therefore, in many cases of idiopathic, recurrent or thrombophilia-related VTE requiring long-term secondary prophylaxis, LMWH was used for this purpose.

Nadroparin 15,000 IU/day s.c. was given to 15 patients, enoxaparin $(1 \mathrm{mg} / \mathrm{kg} /$ day s.c.) to 42 patients and acenocoumarol to 29 patients, doses aimed to reach a target range of INR 2.0-3.0.

Each patient was evaluated twice for bone structure abnormalities: first after 7-10 days of initial treatment for VTE and then after either 3,6,12 or 24 months, depending on the duration of prophylaxis. Bone structure was assessed by densitometry (according to the DEXA method with LUNAR DPX-L, Lunar, Madison, Wisc., USA). Two different bones (femur and lumbar spine $\mathrm{L}_{2}-\mathrm{L}_{4}$ ) were studied. The initial bone mineral density as measured by densitometry was assigned a value of $100 \%$ and compared to the final BMD result, expressed as the percentage difference from the initial value.

Z-score was assessed, defined for individual patients as the number of standard deviations from an ideal BMD value corrected for age and sex.

\section{Results}

We observed a decrease in BMD in most cases; changes were evident in the group treated with nadroparin for 3 months, but this trend was especially evident in the group receiving enoxaparin for 1 year or more. Deterioration of bone structure was also found in the group of patients on acenocoumarol treatment. Progressive changes were noticed in patients receiving $\mathrm{LMWH}$ for 3, 12 or 24 months. Z-score also decreased with time 
Table 1. Changes in bone mineral content during VTE prophylaxis

\begin{tabular}{|c|c|c|c|c|c|c|}
\hline & \multirow[t]{3}{*}{ Patients } & \multirow{3}{*}{$\begin{array}{l}\text { Time } \\
\text { months }\end{array}$} & \multicolumn{4}{|c|}{ Changes in bone mineral content } \\
\hline & & & \multicolumn{2}{|l|}{ Femur } & \multicolumn{2}{|c|}{ Lumbar spine } \\
\hline & & & $\Delta \mathrm{BMD}, \%$ & $\Delta \mathrm{Z}$-score & $\Delta \mathrm{BMD}, \%$ & $\Delta \mathrm{Z}$-score \\
\hline Nadroparin & 15 & 3 & -1.35 & -0.07 & -1.2 & -0.13 \\
\hline Enoxaparin & 24 & 12 & -3.1 & -0.15 & -4.05 & -0.25 \\
\hline Enoxaparin & 18 & 24 & -4.8 & -0.28 & -3.81 & -0.31 \\
\hline Acenocoumarol & 24 & 12 & -1.8 & -0.18 & -1.72 & -0.19 \\
\hline Acenocoumarol & 5 & 24 & -2.55 & -0.31 & -2.32 & -0.28 \\
\hline
\end{tabular}

(table 1). Differences between mean changes of BMD proved statistically significant between the groups of patients treated with enoxaparine and acenocoumarol $(\mathrm{p}<$ 0.005).

\section{Discussion}

In many retrospective studies, LMWH and vitamin K deficiency have been associated with the risk of osteoporosis [15-17].

Data collected on pregnant women suggested an influence of UFH on increased risk of fractures, osteopenia and osteoporosis. The results of the current study which addressed both sexes excluding pregnant women confirmed previous observations. In addition, comparison was made between the influence of LMWH and acenocoumarol, and the results indicated that both drugs cause a BMD decrease, less marked in case of vitamin K antagonists. It seems that these changes correlate with the duration of prophylaxis. Our observations are similar to those published earlier by Monreal et al. [18, 19]. Also the number of patients in both studies was similar though our subgroups were smaller.

Only very few published studies concerned the influence of vitamin $\mathrm{K}$ antagonists on bone structure [20]. With the exception of the study of Jamal et al. [21], all other studies including ours $[22,23]$ suggested deterioration in the indices of bone structure. The reasons for these changes are unclear. The development of histomorphometric and markers for bone metabolism analysis may contribute to explain the influence of vitamin $\mathrm{K}$ antagonists and LMWH on bone density.

This study shows that there is a modest but distinct and progressive decrease in BMD in patients on prolonged anticoagulation after VTE. Peak bone density is normally achieved after puberty and into the third decade of life. At menopause, an acceleration of bone loss occurs over approximately 5-8 years, with an annual 2-3\% loss of trabecular and 1-2\% loss of cortical bone. The data presented here show only mean changes $(\triangle B M D)$ in individual bone areas and they do not allow for a formal diagnosis of osteopenia or osteoporosis. Many of the patients with VTE, including those who might require chronic lifelong secondary prophylaxis, experience a significant decrease in BMD already in baseline densitometry. A further BMD decrease accelerated by vitamin K antagonists, and especially LMWH, may aggravate bone destruction. To what extent such destruction can be prevented by appropriate monitoring and active prophylaxis or treatment of osteoporosis remains to be assessed. Performing densitometry at baseline and thereafter once a year could be helpful but, considering the current numbers of patients receiving anticoagulation, would be a heavy burden on healthcare economics. It should be noticed that the two groups (LMWH and vitamin $\mathrm{K}$ antagonists) may have differed at the start with respect to risk factor for osteoporosis, given the nonrandomized design.

Our results should be useful not only for clinical decision-making regarding the choice of anticoagulation agents but might also serve as a reference for future trials assessing side effects of new drugs, both related and unrelated to heparin, such as pentasaccharides and direct oral thrombin inhibitors and their influence on bone structure.

We conclude that long-term exposure to treatment for VTE causes a consistent, progressive decrease in BMD, more marked with LMWH than with vitamin K antagonists. It would be advisable to perform densitometry before starting secondary prophylaxis with anticoagulants and to repeat it every 12 months, especially in patients who are otherwise at higher risk of developing osteoporosis. 


\section{References}

1 Griffith GC, Nichols G, Asher JD, Flanagan B Heparin osteoporosis. JAMA 1965;193:91-94.

2 Hellgren M, Nygards EB: Long-term therapy with subcutaneous heparin during pregnancy. Gynecol Obstet Invest 1982;13:76-89.

3 De Swiet M, Ward PD, Fidler J, et al: Prolonged heparin therapy in pregnancy causes bone demineralization. Br J Obstet Gynecol 1983;90:1129-1134.

4 Barbour LA, Kick SD, Steiner JF, et al: A prospective study of heparin-induced osteoporosis in pregnancy using bone densitometry. Am J Obstet Gynecol 1994;170:862-869.

5 Ginsberg J, Kowalchuk G, Hirsh J, Brill-Edwards P, Burrows R, Coates G, Weber C: Heparin effect on bone density. Thromb Haemost 1990;64:286-289.

6 Murray WJG: Low molecular weight heparin in surgical practice; MS thesis, London, 1985.

7 Murray WJG, Lindo WS, Kakkar VV, Mellissari E: Long-term administration of heparin fractions and osteoporosis in experimental animals. Blood Coagul Fibrinolysis 1995;6:113118.

8 Nelson-Piercy C, et al: Low molecular weight heparin for obstetric thromboprophylaxis; experience of 69 pregnancies in 61 high-risk women. Am J Obstet Gynecol 1997;176:10621068.

9 Czerchawski L: Pathophysiological basis of using heparin in secondary prophylaxis of venous thromboembolism, Warsaw, 1996, pp 124127.
10 Muir JM, Andrew M, Hirsh J, Weitz JI, Young E, Deschamps P, Shaughnessy SG: Histomorphometric analysis of the effects of standard heparin on trabecular bone in vivo. Blood 1996;88:1314-1320.

11 Muir JM, Weitz JI, Andrew M, Young E, Shaughnessy SG: A histomorphometric comparison of the effects of heparin and low-molecular-weight heparin on cancellous bone in rats. Blood 1997;89:3236-3242.

12 Shaughnessy SG, Young E, Deschamps P, Hirsh J: The effects of low molecular weight and standard heparin on calcium loss from fetal rat calvaria. Blood 1995;86:1368-1373.

13 Hirsh J, Dalen EJ, Anderson DR, Poler L, Bussay H, Ansell J, Deykin D: Oral anticoagulants: Mechanism of action, clinical effectiveness and optimal therapeutic range. Chest 2001;119:821.

14 Goswami A, Leonard JL, Rosenberg IN: Inhibition by coumadin anticoagulants of enzymatic outer ring monodeiodination of iodothyronines. Biophys Res Commun 1982;104:12311238.

15 Kher A, Toulemonde F: Heparin-induced osteoporosis; in Sarret M, Kher A, Toulemonde F (eds): Low Molecular Weight Heparin Therapy. Dekker, New York, 1999, pp 448-449.

16 Mellisari E, et al: Use of low molecular weight heparin in pregnancy. Thromb Haemost 1982; 68:652-656.
17 Walenga JM, Bick RL: Heparin-induced thrombocytopenia, paradoxical thromboembolism and other side effects of heparin therapy. Med Clin N Am 1998;82:635-658.

18 Monreal M, Lafoz E, Olive A, et al: Comparison of subcutaneous unfractionated heparin with low molecular weight heparin (Fragmin) in patients with venous thromboembolism and contraindications to coumarin. Thromb Haemost 1994; 71:7-11.

19 Monreal M, Olive A, Lafoz E, Del Rio L: Heparins, coumarin, and bone density (letter to the editor). Lancet 1991;338:706.

20 Caraballo PJ, Heit JA, Atkinson EJ, Silverstein MD, O'Fallon WM, Castro R, Melton JL: Long-term use of oral anticoagulants and the risk of fracture. Arch Intern Med 1999;159: 1750-1756.

21 Jamal SA, Browner WS, Bauer DC, Cummings SR: Warfarin use and risk for osteoporosis in elderly women. Ann Intern Med 1998;128: 829-832.

22 Wawrzyńska L, Przedlacki J, Hajduk B, Bielska Falda H, Tomkowski W, Torbicki A: Lowmolecular weight heparins, acenocoumarol and bone density (letter to the editor). Haemostasis 2001;31:69-70

23 Wawrzyńska L, Przedlacki J, Hajduk B, Tomkowski W, Fijałkowska A, Ostrowski K, Torbicki A: Secondary prophylaxis with low molecular weight heparins or oral anticoagulants and bone mineral density. Pol Arch Intern Med 2000;5:769-777. 